\title{
Deciphering the differential response of two human fibroblast cell lines following Chikungunya virus infection
}

\author{
Vincent G Thon-Hon ${ }^{1}$, Melanie Denizot ${ }^{1}$, Ghislaine Li-Pat-Yuen², Claude Giry ${ }^{1}$, Marie-Christine Jaffar-Bandjee ${ }^{1,2}$ \\ and Philippe Gasque ${ }^{1 *}$
}

\begin{abstract}
Background: Chikungunya virus (CHIKV) is an arthritogenic member of the Alphavirus genus (family Togaviridae) transmitted by Aedes mosquitoes. CHIKV is now known to target non hematopoietic cells such as epithelial, endothelial cells, fibroblasts and to less extent monocytes/macrophages. The type I interferon (IFN) response is an early innate immune mechanism that protects cells against viral infection. Cells express different pattern recognition receptors (including TLR7 and RIG-I) to sense viruses and to induce production of type I IFNs which in turn will bind to their receptor. This should result in the phosphorylation and translocation of STAT molecules into the nucleus to promote the transcription of IFN-stimulated antiviral genes (ISGS). We herein tested the capacity of CHIKV clinical isolate to infect two different human fibroblast cell lines HS 633T and HT-1080 and we analyzed the resulting type I IFN innate immune response.
\end{abstract}

Methods: Indirect immunofluorescence and quantitative RT-PCR were used to test for the susceptibility of both fibroblast cell lines to CHIKV.

Results: Interestingly, the two fibroblast cell lines HS 633T and HT-1080 were differently susceptible to CHIKV infection and the former producing at least 30-fold higher viral load at $48 \mathrm{~h}$ post-infection (PI). We found that the expression of antiviral genes (RIG-I, IFN- $\beta$, ISG54 and ISG56) was more robust in the more susceptible cell line HS $633 \mathrm{~T}$ at $48 \mathrm{~h} \mathrm{PI}$. Moreover, CHIKV was shown to similarly interfere with the nuclear translocation of pSTAT1 in both cell lines.

Conclusion: Critically, CHIKV can control the IFN response by preventing the nuclear translocation of pSTAT1 in both fibroblast cell lines. Counter-intuitively, the relative resistance of HT-1080 cells to CHIKV infection could not be attributed to more robust innate IFN- and ISG-dependent antiviral responses. These cell lines may prove to be valuable models to screen for novel mechanisms mobilized differentially by fibroblasts to control CHIKV infection, replication and spreading from cell to cell.

Keywords: CHIKV, Type I IFN, HS 633T, HT-1080, RIG-I, TLR7, STAT-1

\footnotetext{
* Correspondence: gasque@univ-reunion.fr

'Immunopathology and Infection Research Grouping (IRG), EA4517,

University of La Reunion, CHU Felix Guyon and CYROI, St Denis, La Reunion,

France

Full list of author information is available at the end of the article
} 


\section{Background}

Chikungunya virus (CHIKV) is an arthritogenic member of the Alphavirus genus (family Togaviridae) transmitted by Aedes mosquitoes [1]. CHIKV is responsible for a febrile illness called CHIK fever which has an incubation period usually comprised between 3 to 7 days (range, 2-12 days) [2,3]. The first cases of patients infected by CHIKV described acute onset of high fever (temperature usually above $38.9^{\circ} \mathrm{C}$ ), severe joint pain, and rash as classic clinical symptoms [4]. CHIKV has been responsible for explosive outbreaks since 2005 in the Indian Ocean. CHIKV targets human non hematopoietic cells including fibroblasts, epithelial, neuronal and endothelial cells and to less extent hematopoietic cells (e.g. monocyte-derived macrophages and primary cultures of macrophages) [5-10]. CHIKV is an enveloped virus and its genome consists in a positive single-stranded RNA molecule of 11805 nucleotides long [11]. It is composed of two open reading frames (ORFs). The 5' ORF encodes non-structural proteins (nsP1 to nsP4) which are multifunctional and form together the virus replicase. The 3' ORF encodes the structural proteins (capsid $[\mathrm{C}]$, envelope glycoproteins [E1 and E2], E3 and 6 k) $[12,13,14]$.

Induction of type I interferons (IFN- $\alpha$ and $\beta$ ) by intracellular sensors such as the Toll-like receptors (TLRs) located in endosomes (e.g. TLR7) and the cytosolic RIGlike receptors (RLRs) (e.g. RIG-I) represents an early innate immune response against viruses [15-18] TLR7 recognizes single-strand RNA [19-21] whereas RIG-I detects viral genomic RNA bearing 5 '-triphosphates, single and double-strand RNAs (dsRNA) [22]. Interaction of RIG-I DExD/H box domain with viral dsRNA induces conformational changes which promotes downstream signaling cascade. The mitochondrial antiviral-signaling protein (MAVS, also known as VISA, Cardiff or IPS-1), an adaptator molecule, is then recruited and activates the tank binding kinase 1 (TBK1 also IKKe in lymphoid cells). TBK1 thus phosphorylates the interferon regulatory factor 3 (IRF-3) at specific serine residues [23,24]. Then IRF-3 dimerizes and translocates into the nucleus to promote the expression of IFN- $\alpha$ and $\beta$ [25]. IFN response is initiated by the binding of type I IFNs to the cell surface IFN- $\alpha / \beta$ receptor (IFNAR) in an autocrine and paracrine manner $[26,27]$. IFNAR subsequently activates the Janus kinases proteins (Jak1 and Tyk2), which in turn phosphorylate signal transducers and activators of transcription 1 and 2 (STAT1 and STAT2) [28]. Phosphorylated STAT1 and STAT2 form heterodimers, migrate into the nucleus and associate with IRF-9 (also known as p48 or ISGF-3y) to form a transcription factor complex termed IFN-stimulated gene factor 3 (ISGF-3) [26]. Active ISGF-3 interacts with a specific DNA sequence called the IFN-stimulated response element (ISRE) present in the promoter region of IFN-stimulated genes (ISGs) to promote ISG transcription. The expression of various ISGs is induced to clear viral infection, including the protein kinase $\mathrm{R}$ (PKR) which activates the shutdown of protein translation [29,30]. Recent investigation of innate immune reaction in human fibroblasts showed that CHIKV induces innate immune activation via the adaptor molecule IPS-1 in human fibroblasts [31]. In this work, we deciphered further the downstream innate immune response of two human fibroblast cell lines HS 633T and HT-1080 infected by CHIKV on the ground that they showed differential capacity to be infected and to replicate CHIKV.

\section{Results}

The human fibroblast cell lines HS 633T and HT-1080 are differently susceptible to CHIKV infection

To evaluate their susceptibility to the virus, HS 633T and HT-1080 cells were grown on glass coverslips in 24 well plates and incubated for $48 \mathrm{~h}$ with a MOI of 1 of the clinical CHIKV isolate clone \#4 [32]. In mock-infected cells (CTL), no CHIKV was detected by immunostaining (Figure 1Aa, c and g, i). At $48 \mathrm{~h}$ post infection (PI), 63.02\% \pm 14.48 of HS 633T cells were stained for CHIKV (Figure 1B). The infection spreads in larger clusters from the initially infected cells (Figure 1Ad, f). Surprisingly at the same time point, only $3.62 \% \pm 1.83$ of HT- 1080 cells were infected by CHIKV (Figure 1B). The infection did not spread in clusters in HT-1080 cells since infected cells were found isolated at $48 \mathrm{~h}$ PI (Figure 1Aj, l). These results indicate that HS 633T are highly susceptible to CHIKV infection while HT-1080 cells are less susceptible. Next, we wanted to evaluate the ability of both fibroblast cell lines to produce viral progeny in the medium. Interestingly at $8 \mathrm{~h}$ post-infection, identical levels of CHIKV RNA copies were detected in the supernatant of both cell lines $\left(1.68 \times 10^{7} \pm 1.23 \times 10^{6}\right.$ viral RNA copies $/ \mathrm{mL}$ in HS $633 \mathrm{~T}$ compared to $1.46 \times 10^{7} \pm 3.70 \times 10^{5}$ in HT-1080) whereas at 24 and $48 \mathrm{~h}$ PI the number of viral RNA copies was clearly higher in HS 633T compared to HT-1080 cells (Figure 1C). For instance, $3.70 \times 10^{8} \pm 6.74 \times 10^{7}$ viral RNA copies/mL were detected in HS633T versus $4.26 \times 10^{7}$ $\pm 2.80 \times 10^{6}$ in HT- 1080 at $24 \mathrm{~h}$ PI. At $48 \mathrm{~h}$ PI the values reached $7.03 \times 10^{9} \pm 5.31 \times 10^{8}$ in HS $633 \mathrm{~T}$ and $2.22 \times 10^{8}$ $\pm 2.45 \times 10^{7}$ in HT-1080).

\section{Robust HS 633T- and milder HT-1080- innate immune responses against CHIKV}

We next investigated whether the expression of antiviral genes from the IFN pathway was differentially modulated by CHIKV in both fibroblast cell lines. We used GAPDH as a housekeeping gene and to compare the relative expression between both cell lines. First, we found that both cell lines expressed equally well the receptors involved in RNA virus sensing (RIG-I and 
$\mathbf{A}$

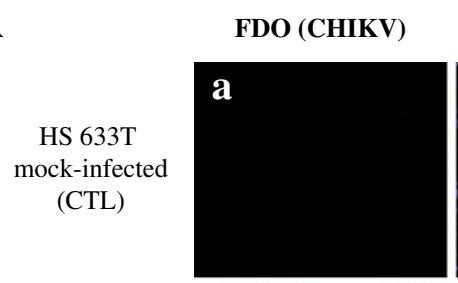

HS 633T

CHIKV $48 \mathrm{~h}$
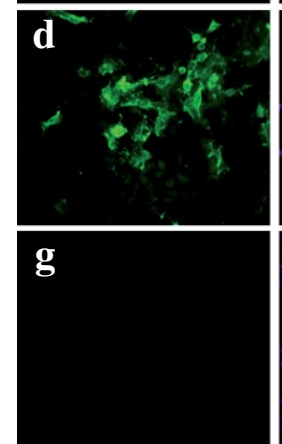

HT- 1080 CHIKV 48h

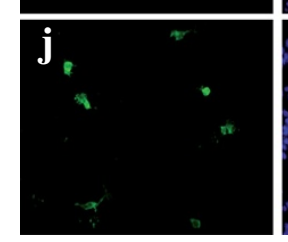

\section{B}

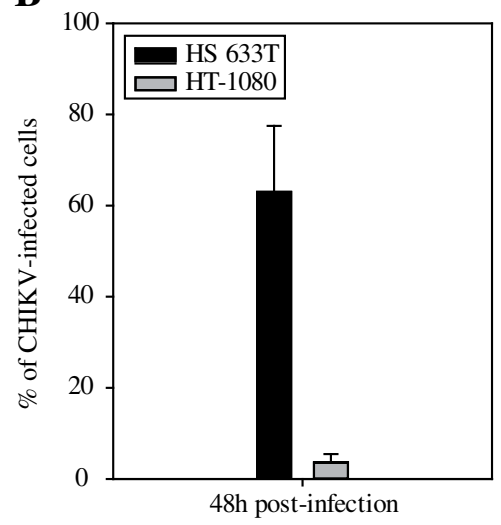

DAPI
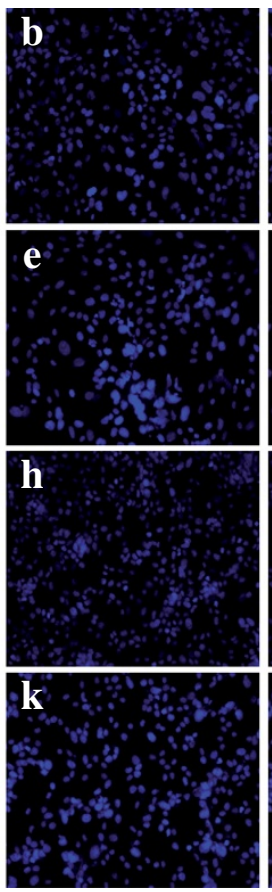

\section{Merge}
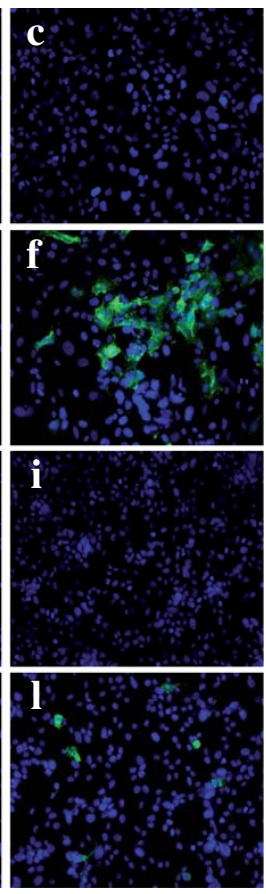

C

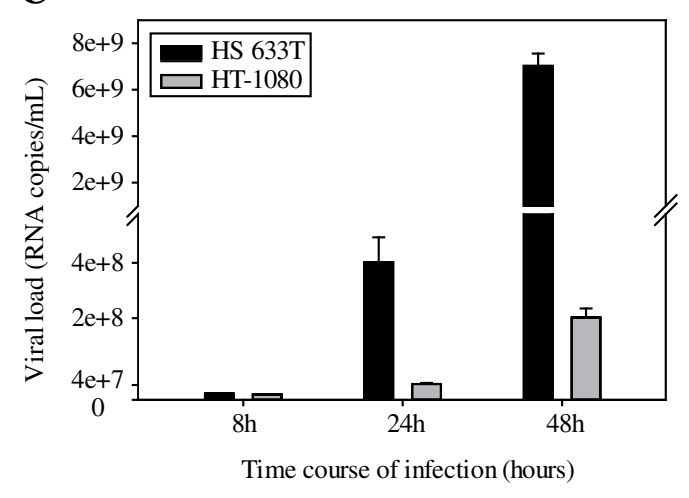

Figure 1 Human fibroblast cell lines HS 633T and HT-1080 are differently susceptible to chikungunya virus (CHIKV) infection. (A) Immunostaining (polyclonal anti-CHIKV, green) of HS 633T and HT-1080 cells infected with CHIKV MOI of 1 ( $d, e, f$ and j, k, I respectively) or mockinfected (a, b, c and $\mathbf{g}, \mathbf{h}$, i respectively). Nuclei were stained with DAPI (blue), view X200. The experiments were performed in triplicate. (B) Percentage of HS 633T and HT-1080 CHIKV-infected (green staining) at a MOI of 1 at $48 \mathrm{~h}$ post-infection. Green fluorescent cells were counted in three observation fields and results are expressed as mean \pm standard error. (C) Quantification of the viral load by real time qRT-PCR from HS 633T and HT-1080 supernatants infected with CHIKV MOI 1 for 8, 24 and 48 h. The experiment was done in duplicate and results are expressed as mean \pm standard error.

TLR7), IFN- $\beta$ and three of the main ISGs (ISG20, ISG54 and ISG56) in basal conditions (Figure 2A, B).

In response to CHIKV infection, the relative expression of RIG-I significantly increased in HS 633T at $8 \mathrm{~h}\left(1.51 \times 10^{-1} \pm\right.$ $\left.1.66 \times 10^{-2}, \mathrm{p}<0.05\right), 24 \mathrm{~h}\left(1.28 \times 10^{-1} \pm 2.29 \times 10^{-2}, \mathrm{p}<0.05\right)$ and $48 \mathrm{~h}$ PI $\left(2.68 \times 10^{-1} \pm 3.12 \times 10^{-2}, \mathrm{p}<0.001\right)$ when compared to mock-infected cells $\left(2.46 \times 10^{-2} \pm 2.02 \times 10^{-3}\right)$ (Figure 2A). The same modifications in RIG-I expression was noted in infected HT-1080 (Figure 2B). Interestingly, we found higher expression of RIG-I in infected HS 633T when compared to infected HT-1080 at $24 \mathrm{~h}(\mathrm{p}<0.05)$ and $48 \mathrm{~h}$ PI $(p<0.001)$. The relative expression of IPS-1 (data not shown) and TLR7 (Figure 2A, B) were not significantly affected in both cell lines following CHIKV infection.

The relative expression of IFN- $\beta$ was increased significantly at $48 \mathrm{~h}$ PI in HS 633T $\left(3.96 \times 10^{-4} \pm 1.67 \times 10^{-4}\right.$, $\mathrm{p}<0.05$ ) (Figure 2A) but was not affected in HT-1080 (Figure 2B). Moreover, the relative expression of IFN- $\beta$ 


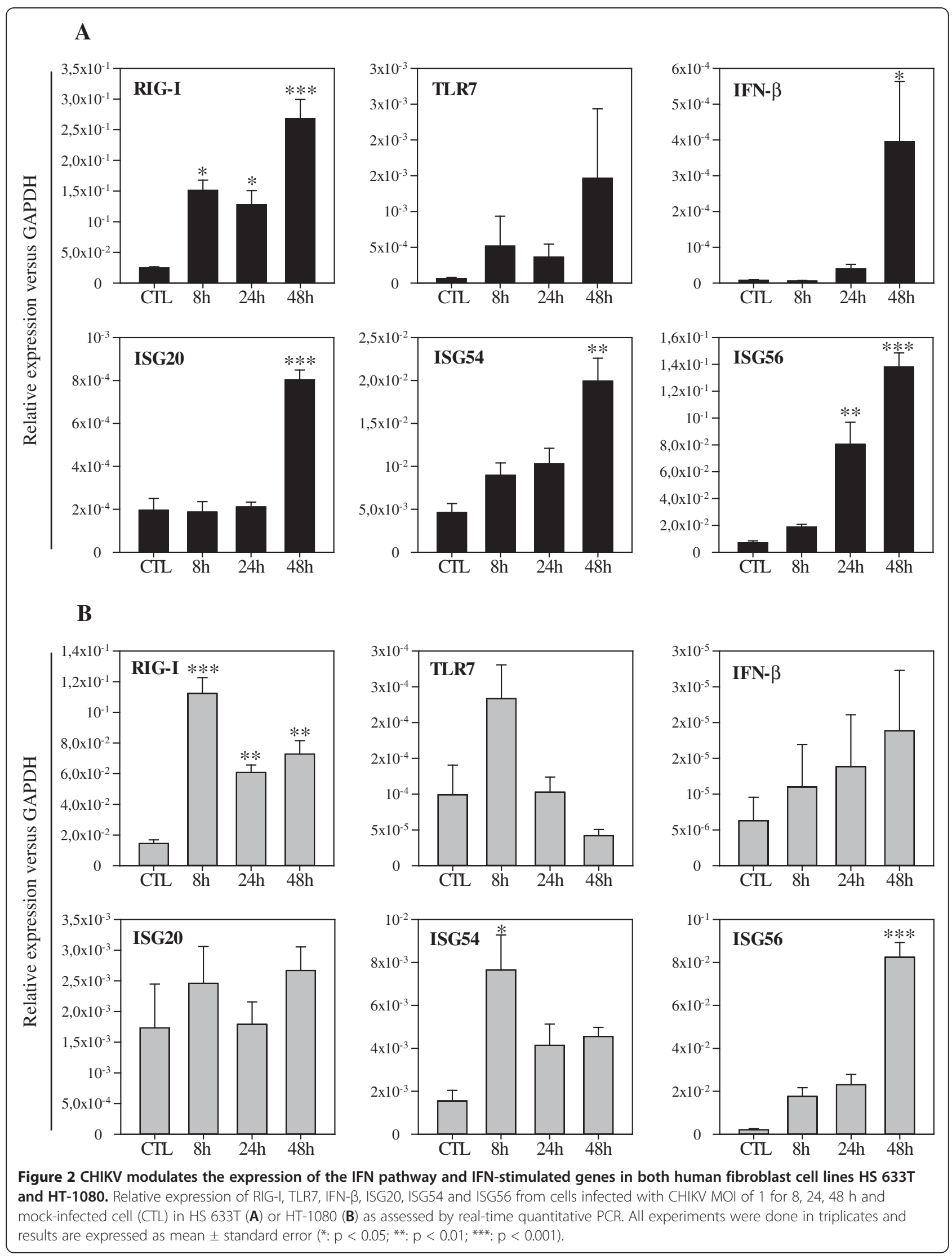


was significantly higher in HS 633T when compared to HT-1080 at 48 h PI $\left(1.89 \times 10^{-5} \pm 8.43 \times 10^{-6}\right.$ for HT-1080, $\mathrm{p}<0.01)$.

All three ISGs tested were significantly upregulated in HS 633T-infected cells at $48 \mathrm{~h}$ PI while more modest upregulation were observed in HT-1080-infected cells for ISG54 ( $8 \mathrm{~h}$ ) and ISG56 (48 h) PI and not for ISG20. For instance, the relative expression of ISG54 was significantly higher in HS 633T than in HT-1080 at $24 \mathrm{~h}\left(1.03 \times 10^{-2} \pm\right.$ $1.84 \times 10^{-3}$ versus $\left.4.14 \times 10^{-3} \pm 9.90 \times 10^{-4}, \mathrm{p}<0.05\right)$ and $48 \mathrm{~h}$ PI $\left(1.99 \times 10^{-2} \pm 2.67 \times 10^{-3}\right.$ versus $4.55 \times 10^{-3} \pm 4.24 \times 10^{-4}$, $\mathrm{p}<0.001$ ). Similarly, the relative expression of ISG56 was significantly higher in HS 633T than in HT-1080 at $24 \mathrm{~h}$ $\left(8.04 \times 10^{-2} \pm 1.65 \times 10^{-2}\right.$ versus $2.31 \times 10^{-2} \pm 4.77 \times 10^{-3}$, $\mathrm{p}<0.001)$ and at $48 \mathrm{~h}$ PI $\left(1.38 \times 10^{-1} \pm 1.05 \times 10^{-2}\right.$ versus $\left.8.24 \times 10^{-2} \pm 6.90 \times 10^{-3}, \mathrm{p}<0.001\right)$.

These results suggest that the relative resistance of HT-1080 to be infected and replicate CHIKV cannot be attributed to higher expression of antiviral genes such as IFN- $\beta$ and ISGs involved in the innate immune response.

\section{CHIKV interferes with the nuclear translocation of PSTAT1 in both HS 633T and HT-1080 cell lines}

We next examined the capacity of CHIKV to control the nuclear translocation of phosphorylated STAT1 (pSTAT1) in both human fibroblast cell lines. As expected, pSTAT1 colocalized with DAPI staining indicating that pSTAT1 translocated into the nucleus of the large majority of HS 633T cells in response to exogenous IFN- $\alpha$ (Figure 3A: $d, e)$. In CHIKV-infected HS 633T cells, CHIKV E1 was detected (Figure 3Ai) whereas pSTAT1 staining (nuclear and cytoplasmic stainings) could not be observed (Figure 3Ah). In CHIKV-infected and subsequently stimulated with IFN- $\alpha$, less than $25 \%$ of cells were pSTAT1+ (Figure 3Ak, p < 0.01) when compared to $100 \%$ following IFN- $\alpha$ stimulation alone. Interestingly, we found that pSTAT1+ nuclei (long arrow) were present in CHIKV negative cells next to infected cells (Figure 3A; large arrow).

To test if CHIKV was capable of interfering with the nuclear translocation of pSTAT1 in both HS 633T and HT-1080, the number of cells stained for nuclear pSTAT1 was counted in either mock-infected (CTL); mock-infected and IFN- $\alpha$ stimulated (IFN- $\alpha$ ); CHIKVinfected (CHIKV); and finally CHIKV-infected (MOI of $1,24 \mathrm{~h}$ ) and subsequently IFN- $\alpha$ stimulated (30 min). In IFN- $\alpha$ stimulated cells, robust levels of nuclear pSTAT 1 were detected in both cell lines (HS 633T: 74.84\% \pm 5.18 and HT-1080: $72.98 \% \pm 4.34)$. In CHIKV-infected and IFN- $\alpha$ stimulated cells, levels of nuclear pSTAT1 significantly decreased in both cell lines (HS 633T: 27.98\% \pm 6.33 and HT-1080: $23.61 \% \pm 6.05, \mathrm{p}<0.01)$. Surprisingly, these results suggest that the difference of susceptibility to CHIKV infection between HS 633T and HT-1080 cells could not be attributed to a differential inhibition of nuclear pSTAT1 to mediate the antiviral response.

\section{Discussion}

CHIKV is well known to infect both non hematopoietic and hematopoietic cells [5-10]. CHIKV not only infects macrophages but also human fibroblasts from cognitive tissues of different origins (skin, synovium) $[5,10]$. Couderc et al. demonstrated that in neonate mice with a mild infection, CHIKV primarily targets muscles, joints and skin fibroblasts, a cellular and tissue tropism similar to that reported in humans [5]. In a seminal study, Sourisseau and colleagues have shown that skin- and lungderived fibroblasts (Hs 789.Sk and MRC5 respectively) were differentially infected by CHIKV [10] but through mechanisms ill-characterized.

In this paper we demonstrated that HS 633T cells behave as a susceptible fibroblast cell line to CHIKV infection in contrast to the other human fibroblast cell line HT-1080 where only a smaller percentage of cells were infected and released CHIKV progenies at lower levels. We hypothesized that this difference could be due to differential expression of TLR7 and/or RIG-I which are key sensors to control CHIKV infection at least in mouse embryonic fibroblasts [9]. Against our expectations, our results didn't support this hypothesis and arguing for the role of additional antiviral mechanisms mobilized differentially by fibroblast cell lines.

The IFN system is a powerful antiviral mechanism capable of controlling most, if not all, virus infections in the absence of a functional adaptative immunity [28]. However, our analysis did not reveal a higher expression of IFN- $\beta$ in HT-1080 and, in contrast, the expression was significantly more robust in HS 633T cells at $48 \mathrm{~h}$ PI probably as a consequence of higher levels of viral RNA within the cells. This result is consistent with a recent study on primary human foreskin fibroblasts (HFs) [31]. White and colleagues demonstrated that infection of HFs by CHIKV triggered the transcription of IFN $-\beta$ at $24 \mathrm{~h}$ PI.

Viruses have also developed several strategies to control the downstream IFN response to replicate, persist and cause chronic diseases. Here, we showed that CHIKV clinical isolate interfered equally well with the nuclear translocation of activated STAT1 in HS 633T and HT-1080 fibroblast cell models even in the presence of exogenous recombinant IFN- $\alpha$. This observation is consistent with recent data studying CHIKV infection in Vero cells using virus recombinant replicons [33]. In their paper, Fros et al. found that CHIKV infection efficiently blocked nuclear translocation of phosphorylated STAT1 in response to either type I or II IFNs. Other Alphaviruses like Semliki forest virus (SFV) and RRV 


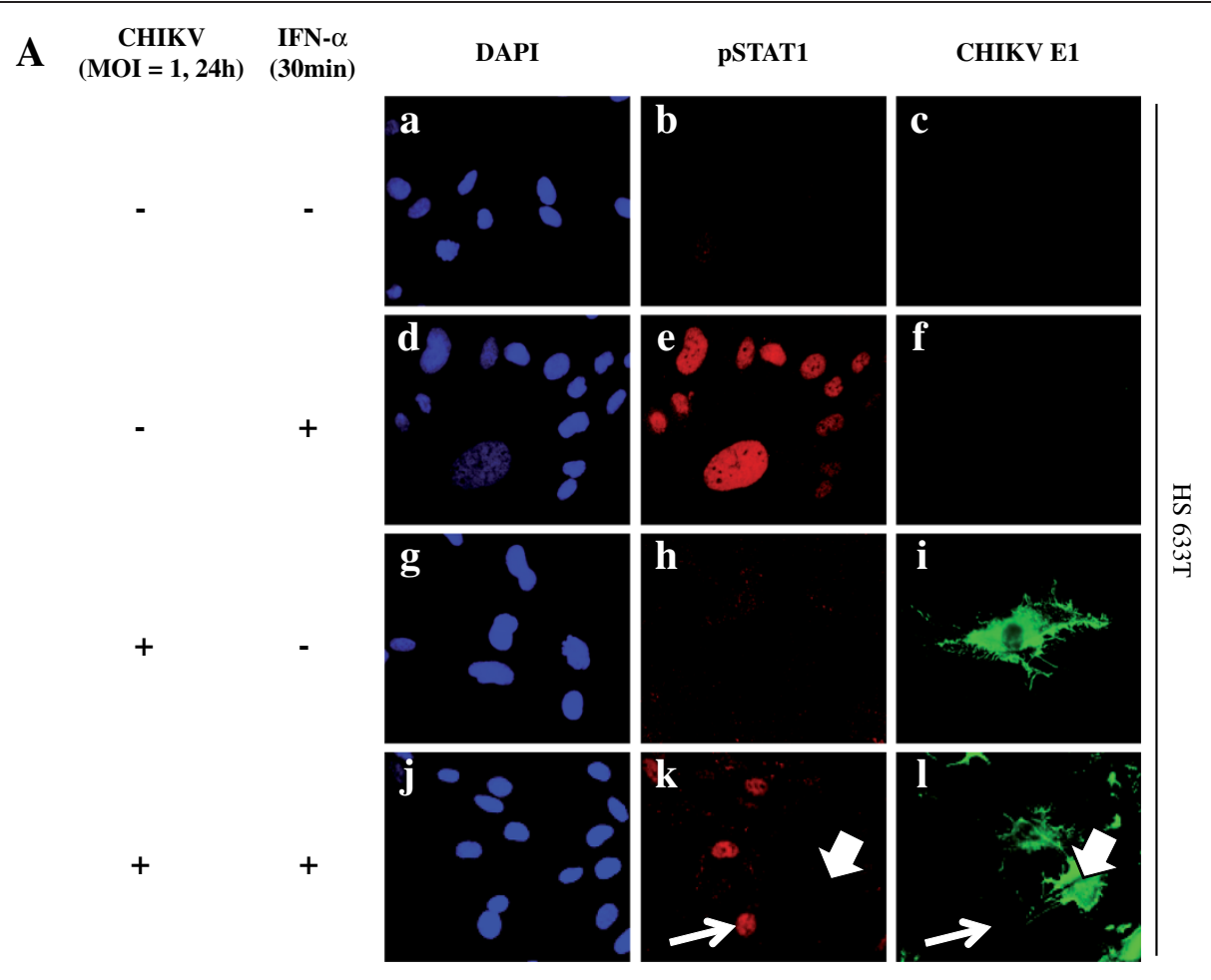

B

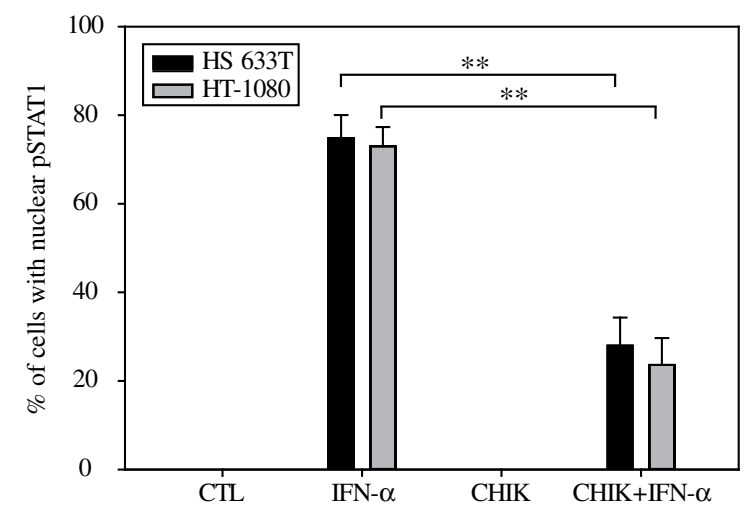

Figure 3 CHIKV interferes equally with the nuclear translocation of phospho-STAT1 in both HS 633T and HT-1080 cells. (A) Double immunostaining was performed for pSTAT1 (red) and CHIKV envelope E1 (green) using HS633T cells either mock-infected (a, b, c); IFN-a-stimulated (d, e, f); CHIKV-infected (g, h, i); and finally CHIKV-infected and IFN-a-stimulated $(j, k, I)$, view X600. Nuclei were stained in blue with DAPI. All experiments were done in triplicate. (B) Percentage of HS 633T or HT-1080 cells with nuclear pSTAT1 from experiments performed in A. Cells were counted in three random fields and the results are expressed as mean \pm standard error $(* *: p<0.01)$.

were also reported to suppress the type I IFN response $[34,35]$.

We cannot exclude the possibility that HT-1080 cells express only low levels of a functional receptor mediating CHIKV entry, yet to be characterized, but it should be stressed that the main differences in terms of susceptibility was not observed at early time point $(8 \mathrm{~h})$ but was evidenced at $24 \mathrm{~h}$ and $48 \mathrm{~h}$. Counter-intuitively, the more resistant HT-1080 was producing lower levels of three main ISGs when compared to HS 633T cells at $48 \mathrm{~h} \mathrm{PI}$.
We should further explore the possible contributions of other antiviral genes such as RNAse-L or PKR to explain differences between HS 633T and HT-1080 fibroblasts.

The analyses of the primary IFN and ISG responses to CHIKV infection did not explain the differences of susceptibility of the two fibroblast cell lines and experiments are now highly warranted to explore further possible additional mechanisms. We and others have recently shown that virus can hide into vesicles (blebs) to enter cells and escape classical recognition and antiviral mechanisms [8] 
which is likely to allow secondary infection of surrounding cells. It will be interesting to analyze the differential capacity of HT-1080 and HS 633T not only to generate and shed these blebs but also to engage macropinocytosis or phagocytosis through specific receptors.

\section{Conclusion}

To sum up, the two human fibroblast cell lines HS 633T and HT-1080 represent good in vitro models to study CHIKV pathogenesis of the cognitive tissue given that they are differently susceptible to infection, replication and to engage an antiviral immune response. Gene profiling of the two cell lines should help to identify the different mechanisms involved in the response to CHIKV infection and subsequent infection of surrounding cells. The capacity of CHIKV to spread from cell to cell at later time point $(>8 \mathrm{~h})$ seems to be independent of the levels of RIG-I, TLR7, type I IFNs and ISGs. It will be essential to explore the contribution of novel cellular pathways such as macropinocytosis or phagocytosis to favor CHIKV infection of surrounding cells in spite of the innate immune response.

\section{Methods}

\section{Cells and virus}

Human fibrosarcoma cell lines, HS 633T and HT-1080 were obtained respectively from European Collection of Cell Cultures (ECACC, 89050201) and Pr Takashi Fujita (Tokyo, Japan). Cells were grown in Dulbecco's Modified Eagle Medium (DMEM eagle, Sigma) supplemented with $10 \%$ fetal bovine serum (FBS) heat inactivated (Dutscher, P04-43100) and completed with $2 \mathrm{mML}$-glutamine (Dutscher, P04-80100), 100U/mL - $0.1 \mathrm{mg} / \mathrm{mL}$ penicillin - streptomycin (Dutscher, P06-07100), $0.5 \mu \mathrm{g} / \mathrm{mL}$ fungizone (Dutscher, P06-01001), $1 \mathrm{mM}$ sodium pyruvate (Dutscher, P04-43100). HS 633T cells were maintained at $37^{\circ} \mathrm{C}$ in a humid atmosphere with $5 \% \mathrm{CO}_{2}$ in Petri dishes. We used a clinical isolate (CHIKV clone \#4) amplified from a patient's serum sample (isolated in our safety level 3 laboratory during the 2006 epidemic) by a single passage on Vero cells [32].

\section{Infection protocol}

All infections were performed with CHIKV clone \#4 at a MOI of 1 . First, to test the susceptibility of the fibroblast cell lines HS 633T and HT-1080, cells were either grown on glass coverslips in 24-well plates or in Petri dishes until $60 \%$ of confluence and then incubated with CHIKV for different periods $(8,24$ and $48 \mathrm{~h}$ PI). Mock-infected cells were prepared as a control. To compare the expression profile of HS 633T and HT-1080 innate immune genes, cells were grown in Petri dishes and infected with CHIKV for the same periods as above. Finally, to analyze the nuclear translocation of pSTAT1 in HS 633T and
HT-1080, cells were grown on glass coverslips in 24-well plates until $40 \%$ of confluence and were either incubated with recombinant human IFN- $\alpha$ alone (Peprotech, 30002A, France) for $30 \mathrm{~min}$ at a final concentration of $100 \mathrm{ng} / \mathrm{mL}$, infected with CHIKV for $24 \mathrm{~h}$ and unstimulated or infected with CHIKV for $24 \mathrm{~h}$ and then incubated with human IFN- $\alpha$ for $30 \mathrm{~min}$ at a final concentration of $100 \mathrm{ng} / \mathrm{mL}$.

\section{Immunofluorescence}

Cells were washed twice in PBS, fixed for $5 \mathrm{~min}$ in cold absolute ethanol, dried for $10 \mathrm{~min}$ and conserved at $-20^{\circ} \mathrm{C}$. Cells were permeabilized with cold acetone for $30 \mathrm{sec}$, washed with PBS and blocked with $1 \%$ BSA in PBS. Coverslips were incubated at $4{ }^{\circ} \mathrm{C}$ overnight in primary antibodies. To evaluate the susceptibility to CHIKV infection of HS 633T and HT-1080, a single immunostaining was performed with a human specific CHIKV antiserum (FDO, 1:4000 dilution). To determine if the nuclear translocation of pSTAT1 in infected HS 633T cells, a double immunostaining was performed with the following primary antibodies: monoclonal mouse anti-CHIKV (1:1000 dilution, as described [32] to detect the E1 envelope glycoprotein (a kind gift from Biomérieux, Marcy l'Etoile, France) or CHIKV antiserum FDO (1:4000 dilution) and polyclonal rabbit anti-human phosphoSTAT1 (1:200 dilution) (Millipore-Chemicon, 07-307). After washings, coverslips were incubated at room temperature for $2 \mathrm{~h}$ in secondary antibodies diluted at 1:1000. Goat anti-human Alexa Fluor 488 IgG $(\mathrm{H}+\mathrm{L})$, goat anti-mouse Alexa Fluor $488 \operatorname{IgG}(\mathrm{H}+\mathrm{L})$ and donkey anti-rabbit Alexa Fluor 594 IgG $(\mathrm{H}+\mathrm{L})$ (Invitrogen Molecular Probes) were used as secondary antibodies. Nuclei were stained with DAPI (Sigma, D9542) at a final concentration of $0.1 \mathrm{ng} / \mathrm{mL}$. Coverslips were mounted in Vectashield (Vector Labs; Cliniscience), and fluorescence was observed using a Nikon Eclips 80i microscope. Images were obtained using the Nikon Digital camera system (Nikon, DXM1200C) and the imaging software NIS-Element BR version 3.1 (Nikon). Cells positive for pSTAT1 were counted in three random fields at 40X to evaluate the inhibition of pSTAT1 nuclear translocation in either HS 633T or HT-1080 mock-infected and unstimulated; mockinfected and IFN- $\alpha$ stimulated; CHIKV-infected and unstimulated; CHIKV-infected and IFN- $\alpha$ stimulated.

\section{Quantitative real-time RT-PCR (CHIKV E1 gene)}

Supernatants were sampled from HS 633T or HT-1080 cell cultures and lysis buffer (NucliSENS ${ }^{\circledR}$ easyMAG ${ }^{\circledR}$, 280134) was added $\mathrm{v} / \mathrm{v}$ in a final volume of $1 \mathrm{~mL}$. Total RNA was extracted from $200 \mu \mathrm{L}$ of supernatants in the easyMAG machine (BIOMERIEUX), according to the manufacturer protocol. A one step qRT-PCR was 
performed in a final volume of $20 \mu \mathrm{L}$ containing $2.5 \mu \mathrm{L}$ of extracted RNA, $10 \mu \mathrm{L}$ of $2 \mathrm{X}$ SuperScript ${ }^{\circledR}$ III Platinum ${ }^{\circledR}$ buffer (invitrogen), $10 \mu \mathrm{M}$ of CHIKV E1 primers (Forward primer: AAG CTY CGC GTC CTT TAC CAA G, Reverse primer: CCA AAT TGT CCY GGT CTT CCT), $5 \mu \mathrm{M}$ of probe (6 Fam-CCA ATG TCY TCM GCC TGG ACA CCT TT-Tamra), 40U/ $\mu \mathrm{L}$ of RNAse Inhibitor (RNAsin, N2511, Promega), $1 \mathrm{U} / \mu \mathrm{L}$ of uracilDNA-glycosylase (UDG, 03539806001, Roche ${ }^{\circledR}$ ), and $0.8 \mu \mathrm{L}$ of SuperScript ${ }^{\circledR}$ III RT/Platinum ${ }^{\circledR}$ Taq Enzyme Mix (invitrogren). qRT-PCRs was carried out in the LightCycler machine (version 1.5, Roche ${ }^{\circledR}$ ) with the following steps: RT at $50^{\circ} \mathrm{C}$ for $20 \mathrm{~min}$, PCR for predenaturation at $95^{\circ} \mathrm{C}$ for $2 \mathrm{~min}, 45$ cycles of denaturation at $95^{\circ} \mathrm{C}$ for $5 \mathrm{sec}$ and annealing at $60^{\circ} \mathrm{C}$ for $1 \mathrm{~min}$.

Quantitative real time RT-PCR for innate immune genes

Total RNA was extracted with Trizol ${ }^{\circledR}$ Reagent (Life Technologies, Cat \# 15596-026). qRT-PCR experiments were done either using a one step qRT-PCR procedure with TaqMan probes or a two step qRT-PCR assay in presence of a DNA-binding dye. All experiments were monitored on a LightCycler ${ }^{\circledR} 480$ Instrument (Roche Diagnostics Ltd). The expression of RIG-I, ISG20, ISG54 and ISG56 (see Table 1) was assessed by a one-step quantitative RT-PCR performed using the One Step PrimeScript $^{\text {tw }}$ RT-PCR kit from TAKARA (Cat \#RR064A, V.0701). Expression of IFN- $\beta$ and TLR7 (see Table 1) was assessed by RT followed by a quantitative PCR using BRYT Green ${ }^{\circledR}$ (Promega, Cat \#A6001/2). In both procedures GAPDH was used as a housekeeping gene against which the gene relative expression was determined according to Pfaffl method [36]. All experiments were done in triplicate and relative expression levels were ploted with the software SigmaPlot version 12.0. Negative controls were included and PCR efficiency was determined from the slope of a dilution curve.

\section{Statistics}

Percentages of infected HS 633T or HT-1080 cells, relative gene expression levels and percentages of HS 633T or HT-1080 cells with nuclear pSTAT1 were expressed as mean \pm standard error (SEM) of 3 independent experiments, each using triplicate culture plates. Comparisons between all treatments (CTL, 8, 24, 48 h PI) for HS 633T or HT-1080 have been analyzed by a One-way ANOVA test. Values of $\mathrm{p}<0.05$ were considered statistically significant for a post-hoc Tukey-Kramer test in order to

Table 1 List of primers for quantitative RT-PCR

\begin{tabular}{|c|c|c|c|c|c|}
\hline Reference & Gene & Primer & $5 '$ modification & Sequence (5' to $\left.3^{\prime}\right)$ & 3' modification \\
\hline \multicolumn{6}{|c|}{ Primer and probes used for the one-step qRT-PCR from TAKARA } \\
\hline \multirow[t]{3}{*}{ NM_002201.4 } & ISG20 & ISG20-636 F & & CTGTTGTGGCGTGAGGCCA & \\
\hline & & ISG20-764R & & TGCCCTCGCATCTTCCACC & \\
\hline & & ISG20-688P & HEX & TGCTGAGTGAGCGCCTCCTGC & $\mathrm{BHQ}-1$ \\
\hline \multirow[t]{3}{*}{ NM_002201.4 } & ISG54 & ISG54-76 F & & GGTCTCTTCAGCATTTATTGGTG & \\
\hline & & ISG54-219R & & TGCCGTAGGCTGCTCTCCA & \\
\hline & & ISG54-124P & FAM & TGCAGCTGCCTGAACCGAGC & BHQ-1 \\
\hline \multirow[t]{3}{*}{ NM_001548.3 } & ISG56 & ISG56-131 F & & GCCTAATTTACAGCAACCATGAG & \\
\hline & & ISG56-347R & & GGCCTTTCAGGTGTTTCACATA & \\
\hline & & ISG56-215P & HEX & TGGGAGTTATCCATTGATGACGATG & BHQ-1 \\
\hline \multirow[t]{3}{*}{ NM_014314.3 } & RIG-I & RIG-I-237 F & & AGCTACATGGCCCCCTGGT & \\
\hline & & RIG-I-397R & & GCATGGTCTAGGGCATCCAA & \\
\hline & & RIG-I-351P & HEX & CAGGAGGAAGGCTGGTTCCGT & BHQ-1 \\
\hline \multirow[t]{3}{*}{ NM_002046 } & GAPDH & GAPDH-F & & AGCCTCAAGATCATCAGCAATG & \\
\hline & & GAPDH-R & & CTGTGGTCATGAGTCCTTCCA & \\
\hline & & GAPDH-P & HEX & CCAACTGCTTAGCACCCCTGGC & BHQ1 \\
\hline \multicolumn{6}{|c|}{ Primers used for the RT-qPCR with BRYT Green } \\
\hline \multirow[t]{2}{*}{ NM_002176.2 } & IFN- $\beta$ & $\mathrm{F}$ & GTTCGTGTTGTCA & & \\
\hline & & $\mathrm{R}$ & TCAATTGCCACAC & & \\
\hline \multirow[t]{2}{*}{ NM_016562.3 } & TLR7 & $\mathrm{F}$ & CCACAACCAACT & & \\
\hline & & $\mathrm{R}$ & CCACCAGACAAA & & \\
\hline \multirow[t]{2}{*}{ NM_002046.3 } & GAPDH & $\mathrm{F}$ & GCACCGTCAAGG & & \\
\hline & & $\mathrm{R}$ & GCCTTCTCCATGC & & \\
\hline
\end{tabular}


compare infected versus control samples. Comparison of gene expression between HS 633T and HT-1080 for each treatment mentioned above has been analyzed by a Twoway ANOVA test. Values of $p<0.05$ were considered statistically significant to perform a Bonferroni post-hoc test. Inhibition of nuclear pSTAT1 translocation in both cell lines has been analyzed with a Student unpaired $t$ test. All statistical tests were done using GraphPad Prism version 5.01. Degrees of significance are indicated in the figure caption as follow: * $\mathrm{p}<0.05$; ${ }^{* * * *} \mathrm{p}<0.01$; ${ }^{* * * *} \mathrm{p}<0.001$.

\section{Competing interests}

The authors declare that they have no competing interests.

\section{Authors' contributions}

PG designed research and secured financial support; VGTH, CG and GLPY performed research; PG, VGTH, MD, MCJB and CG analysed data; VGTH, MD and PG wrote the paper. All authors read and approved the submitted manuscript.

\section{Acknowledgements}

We thank the virology laboratory (CHU Felix Guyon of La Reunion) for supplying the safety level 3 laboratory. We thank Dr Wildriss Viranaicken and Dr Thomas Iwema for their precious advices. We thank Dr Jean-Jacques Hoarau and Dr Pascale Krejbich-Trotot for their technical assistance with the software Sigma Plot version 12.0. We thank Pr Fujita for providing the HT1080 cells.

Financial support was provided by CPER FEDER and ICRES ('integrated chikungunya research' FP7 European program, Ref 261202). The authors received support from INSERM 'contrat d'interface to PG', the French Ministry and ICRES to VGTH. MD is a postdoctoral fellow on the RUN-Emerge FP7 program. Lab funding was also partly from ANR (ANR-06-MIME-040-01) and CRVOI (pathoviro).

\section{Author details}

${ }^{1}$ Immunopathology and Infection Research Grouping (IRG), EA4517, University of La Reunion, CHU Felix Guyon and CYROI, St Denis, La Reunion, France. ${ }^{2}$ Microbiology/Nirology Laboratory, CHU Felix Guyon of La Reunion, St Denis, La Reunion, France.

Received: 21 November 2011 Accepted: 29 August 2012

Published: 20 September 2012

\section{References}

1. Strauss JH, Strauss EG: The alphaviruses: gene expression, replication, and evolution. Microbiol Rev 1994, 58(3):491-562.

2. Borgherini $G$, Poubeau $P$, et al: Persistent arthralgia associated with chikungunya virus: a study of 88 adult patients on reunion island. Clinical infectious diseases: an official publication of the Infectious Diseases Society of America 2008, 47(4):469-475.

3. Staples JE, Breiman RF, et al: Chikungunya fever: an epidemiological review of a re-emerging infectious disease. Clin Infect Dis 2009, 49(6):942-948.

4. Robinson MC: An epidemic of virus disease in Southern Province, Tanganyika Territory, in 1952-53. I. Clinical features. Trans R Soc Trop Med Hyg 1955, 49(1):28-32.

5. Couderc T, Chretien F, et al: A mouse model for Chikungunya: young age and inefficient type-I interferon signaling are risk factors for severe disease. PLoS Pathog 2008, 4(2):e29.

6. Das T, Jaffar-Bandjee MC, et al: Chikungunya fever: CNS infection and pathologies of a re-emerging arbovirus. Prog Neurobiol 2010, 91(2):121-129.

7. Her Z, Malleret B, et al: Active infection of human blood monocytes by Chikungunya virus triggers an innate immune response. J Immunol 2010, 184(10):5903-5913.

8. Krejbich-Trotot $P$, Denizot $M$, et al: Chikungunya virus mobilizes the apoptotic machinery to invade host cell defenses. FASEB J 2010, 25(1):314-325.
9. Schilte C, Couderc T, et al: Type I IFN controls chikungunya virus via its action on nonhematopoietic cells. J Exp Med 2010, 207(2):429-442.

10. Sourisseau M, Schilte $C$, et al: Characterization of reemerging chikungunya virus. PLoS Pathog 2007, 3(6):e89.

11. Khan AH, Morita $\mathrm{K}$, et al: Complete nucleotide sequence of chikungunya virus and evidence for an internal polyadenylation site. J Gen Virol 2002, 83(Pt 12):3075-3084.

12. Strauss EG, Strauss JH: Structure and replication of the alphavirus genome. New York: Plenum Plubishing Corporation; 1986.

13. Faragher SG, Meek AD, et al: Genome sequences of a mouse-avirulent and a mouse-virulent strain of Ross River virus. Virology 1988, 163(2):509-526.

14. Strauss JH, Strauss EG: Evolution of RNA viruses. Annu Rev Microbiol 1988, 42:657-683.

15. Ito T, Amakawa $R$, et al: Interferon-alpha and interleukin-12 are induced differentially by Toll-like receptor 7 ligands in human blood dendritic cell subsets. J Exp Med 2002, 195(11):1507-1512.

16. Iwasaki A, Medzhitov R: Toll-like receptor control of the adaptive immune responses. Nat Immunol 2004, 5(10):987-995.

17. Kato H, Sato S, et al: Cell type-specific involvement of RIG-I in antiviral response. Immunity 2005, 23(1):19-28.

18. Kawai T, Takahashi $\mathrm{K}$, et al: IPS-1, an adaptor triggering RIG-I- and Mda5mediated type I interferon induction. Nat Immunol 2005, 6(10):981-988.

19. Diebold SS, Kaisho T, et al: Innate antiviral responses by means of TLR7-mediated recognition of single-stranded RNA. Science 2004, 303(5663):1529-1531.

20. Heil F, Hemmi H, et al: Species-specific recognition of single-stranded RNA via toll-like receptor 7 and 8. Science 2004, 303(5663):1526-1529.

21. Lund JM, Alexopoulou L, et al: Recognition of single-stranded RNA viruses by Toll-like receptor 7. Proc Natl Acad Sci USA 2004, 101(15):5598-5603.

22. Rehwinkel J, Reis e Sousa C: RIGorous detection: exposing virus through RNA sensing. Science 2010, 327(5963):284-286.

23. Mori M, Yoneyama M, et al: Identification of Ser-386 of interferon regulatory factor 3 as critical target for inducible phosphorylation that determines activation. J Biol Chem 2004, 279(11):9698-9702.

24. Yoneyama M, Suhara $W$, et al: Direct triggering of the type I interferon system by virus infection: activation of a transcription factor complex containing IRF-3 and CBP/p300. EMBO J 1998, 17(4):1087-1095.

25. Yoneyama M, Suhara W, et al: Control of IRF-3 activation by phosphorylation. J Interferon Cytokine Res 2002, 22(1):73-76.

26. Malmgaard L: Induction and regulation of IFNs during viral infections. J Interferon Cytokine Res 2004, 24(8):439-454.

27. Taniguchi T, Takaoka A: The interferon-alpha/beta system in antiviral responses: a multimodal machinery of gene regulation by the IRF family of transcription factors. Curr Opin Immunol 2002, 14(1):111-116.

28. Randall RE, Goodbourn S: Interferons and viruses: an interplay between induction, signalling, antiviral responses and virus countermeasures. J Gen Virol 2008, 89(Pt 1):1-47.

29. Clemens MJ: PKR-a protein kinase regulated by double-stranded RNA. Int J Biochem Cell Biol 1997, 29(7):945-949.

30. Samuel CE: Antiviral actions of interferon. Interferon-regulated cellular proteins and their surprisingly selective antiviral activities. Virology 1991, 183(1):1-11.

31. White LK, Sali T, et al: Chikungunya virus induces IPS-1-dependent innate immune activation and protein kinase R-independent translational shutoff. J Virol 2011, 85(1):606-620.

32. Hoarau JJ, Jaffar Bandjee MC, et al: Persistent chronic inflammation and infection by Chikungunya arthritogenic alphavirus in spite of a robust host immune response. J Immunol 2010, 184(10):5914-5927.

33. Fros JJ, Liu WJ, et al: Chikungunya virus nonstructural protein 2 inhibits type I/II interferon-stimulated JAK-STAT signaling. J Virol 2010, 84(20):10877-10887.

34. Breakwell $L$, Dosenovic $P$, et al: Semliki Forest virus nonstructural protein 2 is involved in suppression of the type I interferon response. J Virol 2007, 81(16):8677-8684. 
35. Lidbury BA, Rulli NE, et al: Identification and characterization of a ross river virus variant that grows persistently in macrophages, shows altered disease kinetics in a mouse model, and exhibits resistance to type I interferon. J Virol 2011, 85(11):5651-5663.

36. Pfaffl MW: A new mathematical model for relative quantification in real-time RT-PCR. Nucleic Acids Res 2001, 29(9):e45.

doi:10.1186/1743-422X-9-213

Cite this article as: Thon-Hon et al: Deciphering the differential response of two human fibroblast cell lines following Chikungunya virus infection. Virology Journal 2012 9:213.

\section{Submit your next manuscript to BioMed Central and take full advantage of:}

- Convenient online submission

- Thorough peer review

- No space constraints or color figure charges

- Immediate publication on acceptance

- Inclusion in PubMed, CAS, Scopus and Google Scholar

- Research which is freely available for redistribution 